\title{
PENGARUH KONSISTENSI TANAH TERHADAP DURASI PELAKSANAAN PONDASI TIANG BOR
}

\author{
Rilo Yansaputra', Jane Sekarsari² \\ ${ }^{1}$ Program Studi Sarjana Teknik Sipil, Universitas Tarumanagara, Jl. Letjen S. Parman No.1 Jakarta \\ Email: rilo.325150210@stu.untar.ac.id \\ ${ }^{2}$ Program Studi Sarjana Teknik Sipil, Universitas Tarumanagara, Jl. Letjen S. Parman No.1 Jakarta \\ Email: tamtana.js@gmail.com
}

\begin{abstract}
ABSTRAK
Perancangan konstruksi pondasi memerlukan penyelidikan geoteknik untuk menentukan stratifikasi dan karakteristik teknis tanah. Studi sebelumnya menunjukkan adanya keterbatasan informasi pada penyelidikan geoteknik yang disebabkan oleh ketidakteraturan lapisan tanah dan sifat tanah yang dapat berbeda drastis dalam jarak hanya beberapa meter saja (heterogen). Keterbatasan informaasi data menimbulkan ketidakpastian. Dari segi perancangan dan pelaksanaan pondasi sudah memiliki ketidakpastian yang merupakan sebuah kendala, mengakibatkan durasi pelaksanaannya menjadi terlambat dari durasi yang telah direncanakan. Hasil tinjauan pustaka menjelaskan bahwa memanfaatkan informasi data kuantitatif di lapangan dan laboratorium seperti uji sondir atau standard penetration test (SPT) dapat diperkiraan distribusi tingkat kesulitan pengeboran. Studi ini bertujuan menganalisis dan mengetahui pengaruh konsistensi tanah yang diwakilkan oleh parameter tanah terhadap durasi pelaksanaan pondasi tiang bor, dengan menggunakan data hasil SPT yang disajikan pada bor log dan durasi pengeboran tiap tiang bor pada proyek gedung bertingkat. Data diolah melalui tahapan elaborasi data bor log untuk mengetahui klasifikasi jenis tanah dan perhitungan durasi berdasarkan rasio $\mathrm{N}_{\mathrm{Spt}}$ (jumlah pukulan pada uji SPT). Data dianalisis sesuai klasifikasi jenis tanah dengan variabel independen $\left(\mathrm{N}_{\mathrm{Spt}}\right.$ dan tebal lapisan) dan variabel dependen (durasi pengeboran). Data dianalisis dengan metode regresi linear berganda. Hasil studi adalah persamaan regresi linear berganda yang bisa menjadi prediktor durasi pengeboran pada pelaksanaan pondasi tiang bor.
\end{abstract}

Kata kunci: pondasi tiang bor, konsistensi tanah, prediktor durasi

\section{PENDAHULUAN}

Perancangan konstruksi pondasi memerlukan penyelidikan geoteknik untuk menentukan stratifikasi tanah dan karakteristik teknis tanah. Penyelidikan geoteknik dilakukan dengan cara sampling tanah yang dijadikan sebagai acuan saat mendesain pondasi seperti penentuan dimensi dan kedalam dari pondasi.

Berdasarkan Anondho dan Sandjaja (2008) menyatakan bahwa keterbatasan informasi pada penyelidikan geoteknik disebabkan oleh ketidakteraturan lapisan tanah dan sifat tanah yang dapat berbeda drastis dalam jarak hanya beberapa meter saja (heterogen). Keterbatasan informaasi data menimbulkan ketidakpastian. Dilihat dari segi perancangan dan pelaksanaan pondasi sudah memiliki ketidakpastian yang merupakan sebuah kendala, sehingga mengakibatkan durasi pelaksanaannya menjadi terlambat dari durasi yang telah direncanakan.

Berdasarkan studi yang dilakukan Roskarina (2008) menunjukkan adanya pengaruh konsistensi tanah yang diwakilkan oleh beberapa parameter tanah terhadap durasi pelaksanaan pondasi tiang pancang.

Oleh karena itu, tujuan yang ingin dicapai studi ini adalah menganalisis dan mengetahui pengaruh konsistensi tanah terhadap durasi pelaksanaan pondasi tiang bor, sehingga diperoleh bentuk persamaan garis regresi linear berganda yang dapat memprediksi durasi pengeboran pada pelaksanaan pondasi tiang bor.

\section{TINJAUAN PUSTAKA}

Nilai $\mathrm{N}_{\mathrm{Spt}}$ atau jumlah blow yang diperlukan pada $15 \mathrm{~cm}$ penetrasi kedua dan ketiga. Hasil pengujian SPT ini disajikan dalam bentuk grafik pada Boring Log bersama dengan deskripsi lapisan tanah. Pada studi ini tanah akan digolongkan menjadi beberapa nama utama yaitu tanah dengan sifat fisik nonkohesif (tanah gravel dan sand ) dan tanah dengan sifat fisik kohesif (tanah silt dan clay). 


\section{Konsistensi Tanah Berbutir Kasar (Tanah Nonkohesif)}

Pengujian SPT telah digunakan dalam korelasi dengan berat isi, kepadatan relatif tanah pasir, modulus elastisitas tanah, sudut geser dalam tanah, dan kohesi tak terdrainase berdasarkan hubungan empiris. Berikut adalah tabel korelasi empiris yang sering digunakan untuk interpretasi hasil uji SPT dengan konsistensi tanah berbutir kasar:

Tabel 1. Konsistensi tanah berbutir kasar yang diukur dari kepadatan relatif (sumber: Rahardjo, 2005)

\begin{tabular}{cc}
\hline Kerapatan Relatif & $\mathrm{N}_{\mathrm{Spt}}$ \\
\hline Sangat Lepas (Very Loose) & $0-4$ \\
\hline Lepas-Lepas (Loose) & $4-10$ \\
\hline Sedang (Medium Dense) & $10-30$ \\
\hline Rapat (Dense) & $30-50$ \\
\hline Sangat Rapat (Very Dense) & $>50$ \\
\hline
\end{tabular}

\section{Konsistensi Tanah Berbutir Halus (Tanah Kohesif)}

Konsistensi tanah untuk tanah berbutir halus dinyatakan dengan kekuatan desak bebas (unconfined compressive strength) atau qu yaitu tegangan yang mematahkan contoh tanah sampai 20\%. Nilai qu ini ditentukan dengan aparat pemadat pada tanah tak terganggu (undisturbed soil sample). Berikut adalah uraian nilai desak yang berkaitan dengan konsistensi pada tanah berbutir halus:

Tabel 2. Konsistensi tanah berbutir halus secara kualitatif dan kuantitatif (sumber: Das, 2011)

\begin{tabular}{cccc}
\hline Konsistensi & Identifikasi Lapangan & $\mathrm{q}_{\mathrm{u}}\left(\mathrm{kg} / \mathrm{cm}^{2}\right)$ & $\mathrm{N}_{\mathrm{Spt}}$ \\
\hline Sangat Lunak (Very Soft) & $\begin{array}{c}\text { Mudah ditekan beberapa inci dengan kepalan } \\
\text { tangan, desakan }\end{array}$ & $<0.25$ & $<2$ \\
\hline Lunak (Soft) & Mudah ditekan beberapa inci dengan ibu jari & $0.25-0.5$ & $2-4$ \\
\hline Sedang (Medium Stiff) & $\begin{array}{c}\text { Dapat ditekan beberapa inci dengan ibu jari agak } \\
\text { mudah }\end{array}$ & $0.5-1.0$ & $4-8$ \\
\hline Kaku (Stiff) & Mudah diiris dengan ibu jari & $1.0-2.0$ & $8-15$ \\
\hline Sangat Kaku (Very Stiff) & $\begin{array}{c}\text { Mudah diiris dengan ibu jari tetapi memerlukan } \\
\text { banyak kekuatan untuk menekan }\end{array}$ & $2.0-4.0$ & $15-30$ \\
\hline Keras (Hard) & Sukar diiris dengan ibu jari & $>4.0$ & $>30$ \\
\hline
\end{tabular}

\section{Konsistensi Tanah Berbutir Kasar (Tanah Nonkohesif)}

Semakin besar nilai konsistensi suatu lapisan tanah maka akan semakin sulit lapisan tanah tersebut untuk dibor. Menurut Seeley (1995) secara umum sulit untuk membuat tingkat kesulitan pengeboran secara pasti, tetapi dengan menggabungkan informasi data kuantitatif di lapangan dan laboratorium (uji sondir atau SPT), dapat diperkirakan distribusi tingkat kesulitan tersebut

Menurut Yassin (2019) durasi pengeboran tidak hanya dipengaruhi oleh tingkat kesulitan pengeboran yang diwakilkan oleh besaran $\mathrm{N}_{\mathrm{Spt}}$ atau tahanan ujung konus (qc) pada uji sondir. Ketebalan suatu lapisan tanah dengan konsitensi tertentu juga dapat memengaruhi durasi pengeboran. Contohnya ada dua lapisan tanah yang memiliki nilai $\mathrm{N}_{\mathrm{Spt}}$ yang sama, namun lapisan tanah yang pertama memiliki tebal lapisan yang lebih besar dari tebal lapisan kedua, maka lapisan pertama lah yang memiliki durasi lebih lama.

\section{METODOLOGI PENELITIAN}

Metode penelitian dimulai dengan melakukan pengumpulan data untuk topik analisis pengaruh konsistensi tanah terhadap durasi pelaksanaan pondasi tiang bor. Jika data yang dibutuhkan sudah terkumpul maka data-data tersebut diolah sesuai dengan jenis tanah dan konsistensinya. Data-data yang sudah diolah tersebut lalu dianalisis dengan menggunakan analisis regresi linear berganda.

\section{Pengumpulan Data}

Pengumpulan data dilakukan dengan tujuan memperoleh data penyelidikan geoteknik dan laporan pelaksanaan pekerjaan pondasi tiang bor di beberapa proyek gedung bertingkat. Variabel yang dibutuhkan dari data tersebut adalah data bor log dari setiap proyek untuk mengetahui konsistensi tanah berdasarkan banyak blow dari standard penetration test $\left(\mathrm{N}_{\mathrm{Spt}}\right)$ dan kedalaman suatu jenis tanah, volume pekerjaan yang diperoleh dari kedalaman ujung tiang dikali luasan dimensi penampang tiang bor, dan data proyek mengenai durasi pengeboran tiap tiang bor. 


\section{Diagram Alir Penelitian}

Studi ini ingin melakukan analisis pengaruh konsistensi tanah terhadap durasi pengeboran pada pelaksanaan pondasi tiang bor yang dapat dilihat seperti pada diagram alir berikut ini:

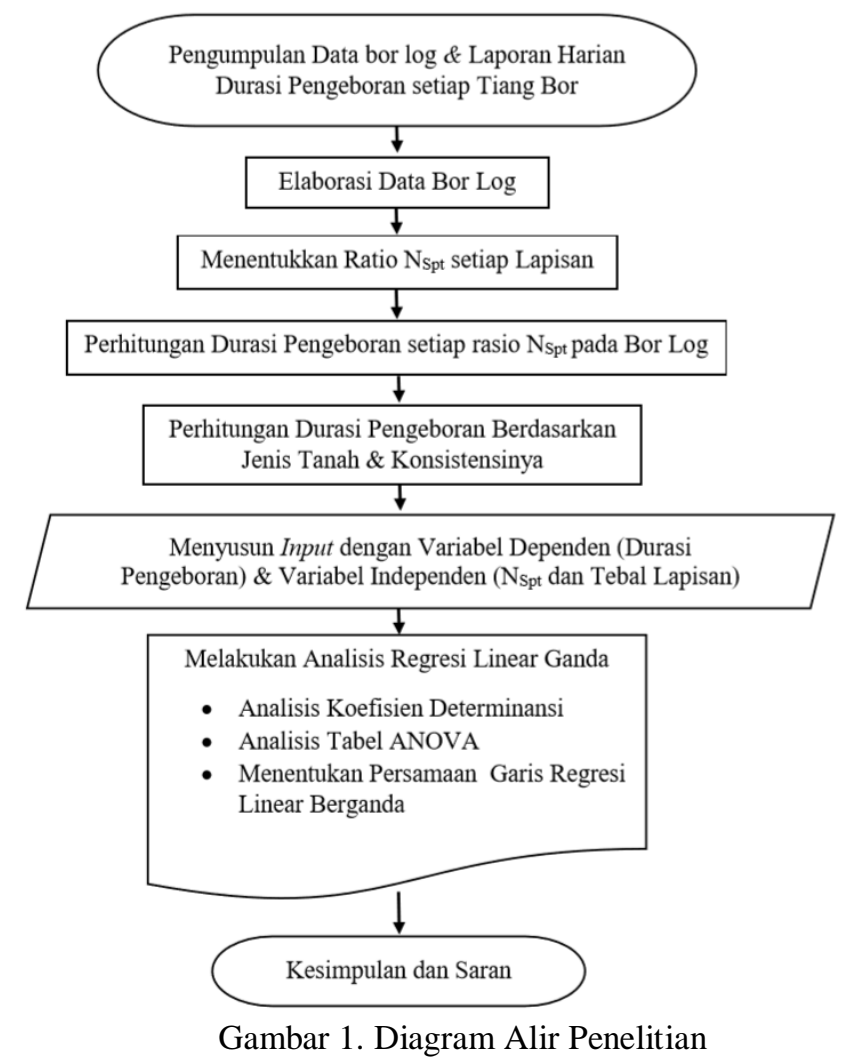

\section{Elaborasi Data Bor Log}

Informasi banyak blow pada standard penetration test $\left(\mathrm{N}_{\mathrm{Spt}}\right)$ dan jenis tanah yang tersedia di data bor log dapat kita kelompokan untuk mengetahui konsistensi suatu lapisan tanah, lihat tabel 1. dan 2.

Setelah jenis tanah dan konsistensinya diketahui selanjutnya dilakukan dengan penggambaran potongan penyelidikan tanah yang dilakukan. Penggambaran dilakukan sampai mencapai kedalaman ujung tiang bor. Untuk proyek yang memiliki penyelidikan tanah lebih dari satu dan ada denah pondasi maupun denah penyelidikan tanah, maka jenis tanah suatu tiang ditentukan dari parameter yang paling dekat dengan tiang tersebut. Gambaran potongan hasil elaborasi data bor log dapat dilihat pada gambar 2.
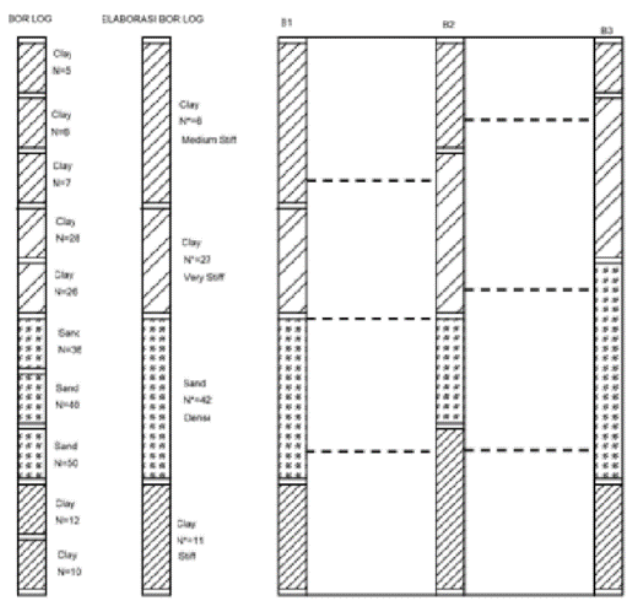

\begin{tabular}{|c|c|c|c|c|c|}
\hline \multicolumn{6}{|c|}{ 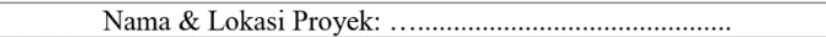 } \\
\hline \multicolumn{3}{|c|}{ Kode Bor log } & \multicolumn{3}{|c|}{ Elaborasi Data Bor Log } \\
\hline $\begin{array}{l}\text { Elevasi } \\
\text { (m) }\end{array}$ & $\mathrm{N}_{\text {Spt }}$ & $\begin{array}{l}\text { Jenis } \\
\text { Tanah }\end{array}$ & $\mathrm{N}_{\mathrm{Spt}} *$ & Konsitensi & $\begin{array}{c}\text { Tebal Lapisan } \\
\text { (m) }\end{array}$ \\
\hline $\mathrm{Ei}$ & $\mathrm{Ni}$ & \multirow{8}{*}{ ૫i } & \multirow{5}{*}{$N^{*} \mathrm{i}$} & \multirow{5}{*}{$\mathrm{Ki}$} & \multirow{5}{*}{ hi } \\
\hline$:$ & : & & & & \\
\hline : & $:$ & & & & \\
\hline$:$ & : & & & & \\
\hline : & : & & & & \\
\hline : & : & & : & : & : \\
\hline : & : & & \multirow{2}{*}{ : } & \multirow{2}{*}{ : } & \multirow{2}{*}{ : } \\
\hline : & $:$ & & & & \\
\hline : & : & \multirow{4}{*}{ un } & : & : & : \\
\hline : & : & & & \multirow{3}{*}{$\mathrm{Kn}$} & \multirow{3}{*}{$\mathrm{hn}$} \\
\hline$:$ & $:$ & & $\mathrm{N}^{*} \mathrm{n}$ & & \\
\hline En & $\mathrm{Nn}$ & & & & \\
\hline
\end{tabular}

Gambar 2. Elaborasi Data Bor Log 


\section{Perhitungan Durasi Pengeboran}

Pada studi yang dilakukan oleh Anondho dan Sandjaja (2008) perhitungan rasio nilai tahanan ujung konus pada uji sondir (qc) dan ketebalan tanah dijadikan dasar dalam menghitung durasi setiap lapisan tanah di suatu proyek untuk setiap titik tiang bor. Karena pada studi ini data yang digunakan adalah pondasi tiang bor dengan elevasi ujung tiang lebih dari 20 meter maka rasio qc tidak bisa memperkirakan distribusi tingkat kesulitan pengeboran dengan alasan pengujian sondir umumnya dilaksanakan hingga kedalaman maksimum $20 \mathrm{~m}$ atau hingga diperoleh nilai tahanan ujung qc $=250 \mathrm{~kg} / \mathrm{cm} 2$. Maka pada studi ini perhitungan rasio $\mathrm{N}_{\mathrm{Spt}}$ dan ketebalan tanah dijadikan dasar dalam menghitung durasi setiap lapisan tanah di suatu proyek untuk setiap titik tiang bor.

Hasil perhitungan berupa distribusi durasi per $\mathrm{m}^{2}$, yaitu membagi durasi pengeboran tiap tiang dalam menit dengan luas penampang tiang bor.

$$
\mathrm{D}=\frac{\mathrm{Di}}{0.25 \times \pi \times \emptyset^{2}}
$$

Durasi pengeboran tiap rasio $\mathrm{N}_{\mathrm{Spt}}$ pada bor log adalah mengkalikan rasio $\mathrm{N}_{\mathrm{Spt}}$ pada tiap lapisan tersebut dengan durasi pengeboran tiap tiang.

$$
\mathrm{Dx}=\frac{\mathrm{Ni}}{\sum \mathrm{N}} \times \mathrm{D}
$$

Durasi pengeboran tiap meter pada bor log adalah mebagi durasi pengeboran Dx dengan ketebalan lapisan.

$$
\mathrm{Dx}^{*}=\frac{\mathrm{Dx}}{\mathrm{h}}
$$

dengan $\mathrm{Di}=$ Durasi pengeboran tiap tiang (menit), $\mathrm{D}=$ Durasi pengeboran tiap tiang bor per meter persegi $\left(\mathrm{menit} / \mathrm{m}^{2}\right)$, $\varnothing=$ Diameter penampang tiang bor, $\mathrm{Ni}=$ Banyak blow pada standard penetration test, $\sum \mathrm{N}=\mathrm{Jumlah}$ total blow pada seluruh lapisan bor log sampai di ujung tiang bor, Dx=Durasi pengeboran tiap rasio $\mathrm{N}_{\mathrm{Spt}}$ pada bor log $\left(\mathrm{menit} / \mathrm{m}^{2}\right)$, $\mathrm{h}=$ Tebal tiap lapisan (meter), dan Dx*=Durasi pengeboran tiap meter pada bor log $\left(\mathrm{menit} / \mathrm{m}^{2} / \mathrm{m}\right)$

\section{HASIL DAN ANALISIS}

Data-data yang digunakan diperoleh dari PT Cokro Pondasi dan PT Tarumanegara Bumiyasa. Data yang digunakan berupa durasi pengeboran setiap titik tiang bor dan penyelidikan geoteknik dari beberapa proyek, yaitu:

1. Proyek Rumah Susun Paspampres Tanah Abang, Jakarta. Di proyek ini terdapat 5 bor log, dan durasi dari setiap titik pengeboran tiang bor.

2. Proyek Kantor Terpadu Kabupaten Sukoharjo, Jawa Tengah. Di proyek ini terdapat 1 bor log, dan durasi dari setiap titik pengeboran tiang bor.

3. Proyek Pasar Pulung Kencana, Lampung. Di proyek ini terdapat 1 bor log, dan durasi dari setiap titik pengeboran tiang bor.

4. Proyek Hotel All Season, Jakarta. Di proyek ini terdapat 1 bor log, dan durasi dari setiap titik pengeboran tiang bor.

Data tersebut akan diolah melalui tahapan elaborasi data bor log, perhitungan durasi pengeboran tiap rasio $\mathrm{N}_{\mathrm{Spt}}$ pada bor log, dan menghitung durasi pengeboran berdasarkan elaborasi data bor log.

\section{Elaborasi Data Bor Log}

Dari data bor log yang telah di peroleh lalu dilakukan elaborasi data bor log yang menghasilkan jenis tanah dan konsistensinya berdasarkan nilai dari $\mathrm{N}_{\text {Spt }}$. Elaborasi bor log dilakukan dengan cara mengelompokkan nilai $\mathrm{N}_{\text {Spt }}$ pada bor log sampai elevasi ujung tiang bor berdasarkan tabel 1. dan 2., sebagai contoh tabel 3. merupakan contoh elaborasi data bor log di Proyek 2:

- $\quad$ Lapisan tanah di elevasi -0 sampai dengan -8 meter tergolong tanah clay konsistensi stiff karena lapisan tersebut memiliki nilai $\mathrm{N}_{\mathrm{Spt}}$ diantara 8 sampai dengan 15, sehingga tanah clay konsistensi stiff tersebut memiliki nilai $\mathrm{N}_{\mathrm{Spt}}$ rata-rata $\left(\mathrm{N}_{\mathrm{Spt}}{ }^{*}\right)$ sebesar $11.5 \approx 12$ dengan tebal lapisan 8 meter. (Lihat tabel 3.) 
Tabel 3. Contoh hasil elaborasi data bor log proyek 2

\begin{tabular}{|c|c|c|c|c|c|}
\hline \multirow[b]{2}{*}{ Elevasi (m) } & \multirow[b]{2}{*}{$\mathrm{N}_{\mathrm{Spt}}$} & \multirow[b]{2}{*}{ Jenis Tanah } & \multicolumn{3}{|c|}{ Elaborasi Bor Log } \\
\hline & & & $\mathrm{N}_{\mathrm{Spt}} *$ & Konsitensi & Tebal Lapisan (m) \\
\hline-2 & 12 & \multirow{12}{*}{ Clay } & \multirow{4}{*}{12} & \multirow{4}{*}{ stiff } & \multirow{4}{*}{8} \\
\hline-4 & 9 & & & & \\
\hline-6 & 12 & & & & \\
\hline-8 & 13 & & & & \\
\hline-10 & 18 & & & \multirow{4}{*}{ very stiff } & \multirow{4}{*}{8} \\
\hline-12 & 15 & & 16 & & \\
\hline-14 & 15 & & 16 & & \\
\hline-16 & 16 & & & & \\
\hline-18 & 11 & & 11 & stiff & 2 \\
\hline-20 & 22 & & \multirow{2}{*}{23} & \multirow{2}{*}{ very stiff } & \multirow{2}{*}{4} \\
\hline-22 & 23 & & & & \\
\hline-24 & 33 & & 33 & hard & 2 \\
\hline-26 & 38 & \multirow{2}{*}{ Sand } & 38 & dense & 2 \\
\hline-28 & 22 & & 22 & medium dense & 2 \\
\hline
\end{tabular}

Dari hasil elaborasi data bor log seluruh proyek, maka jenis tanah dan konsistensinya yang akan dianalisis sesuai tabel 4,

Tabel 4. Klasifikasi jenis tanah yang akan dianalisis

\begin{tabular}{cclcc}
\hline Sifat Fisik & \multicolumn{2}{c}{ Tanah Kohesif } & Tanah Nonkohesif \\
\hline Jenis Tanah & \multicolumn{2}{c}{ Clay } & \multicolumn{1}{c}{ Silt } & Sand \\
\hline \multirow{3}{*}{ Konsistensi } & $\bullet \quad$ Medium stiff & $\bullet$ Very stiff & $\bullet$ Dense to very dense \\
\cline { 2 - 4 } & $\bullet \quad$ Stiff & $\bullet$ Hard & \\
\cline { 2 - 4 } & $\bullet \quad$ Very stiff & & \\
\cline { 2 - 4 } & $\bullet \quad$ Hard & & \\
\hline
\end{tabular}

\section{Perhitungan Durasi Pengeboran tiap Rasio $\mathbf{N}_{\mathrm{Spt}}$ pada Bor Log}

Perhitungan durasi pengeboran tiap rasio $\mathrm{N}_{\text {Spt }}$ dalam suatu proyek untuk setiap titik tiang bor dengan menggunakan rumus yang telah dijelaskan di subbab Perhitungan Durasi Pengeboran. Tabel 5. merupakan contoh perhitungan durasi pengeboran untuk titik tiang bor BP101 dengan diameter 0.8 meter dan durasi pengeboran 150 menit pada Proyek 2.

Tabel 5. Contoh perhitungan durasi pengeboran tiap rasio $\mathrm{N}_{\mathrm{Spt}}$ pada bor log proyek 2

\begin{tabular}{|c|c|c|c|c|c|}
\hline Elevasi & $\mathrm{N}_{\mathrm{Spt}}(\mathrm{Ni})$ & Total $\mathrm{N}_{\mathrm{Spt}}\left(\sum \mathrm{N}\right)$ & Rasio $N_{\text {Spt }}$ & Dx $\left(\right.$ menit $\left./ \mathrm{m}^{2}\right)$ & $\mathrm{Dx}^{*}\left(\mathrm{menit} / \mathrm{m}^{2} / \mathrm{m}\right)$ \\
\hline-2 & 12 & \multirow{14}{*}{259} & 0.0463 & 13.826 & 6.913 \\
\hline-4 & 9 & & 0.0347 & 10.37 & 5.185 \\
\hline-6 & 12 & & 0.0463 & 13.826 & 6.913 \\
\hline-8 & 13 & & 0.0502 & 14.978 & 7.489 \\
\hline-10 & 18 & & 0.0695 & 20.739 & 10.37 \\
\hline-12 & 15 & & 0.0579 & 17.283 & 8.641 \\
\hline-14 & 15 & & 0.0579 & 17.283 & 8.641 \\
\hline-16 & 16 & & 0.0618 & 18.435 & 9.217 \\
\hline-18 & 11 & & 0.0425 & 12.674 & 6.337 \\
\hline-20 & 22 & & 0.0849 & 25.348 & 12.674 \\
\hline-22 & 23 & & 0.0888 & 26.5 & 13.25 \\
\hline-24 & 33 & & 0.1274 & 38.022 & 19.011 \\
\hline-26 & 38 & & 0.1467 & 43.783 & 21.891 \\
\hline-28 & 22 & & 0.0849 & 25.348 & 12.674 \\
\hline
\end{tabular}


Durasi pengeboran untuk tiap rasio $\mathrm{N}_{\text {Spt }}$ pada bor log, yang memiliki ketebalan 2 meter. Berikut ini adalah contoh perhitungan durasi pengeboran tiap rasio $\mathrm{N}_{\mathrm{Spt}}$ pada bor log di elevasi -4 sampai dengan -6 meter :

$$
\mathrm{Dx}=\frac{\mathrm{Ni}}{\sum \mathrm{Ni}} \times \frac{\mathrm{Di}}{0.25 \times \pi \times \emptyset^{2}} \Rightarrow \frac{\mathrm{Ni}}{\sum \mathrm{Ni}}=\frac{12}{259}=0.0463 \Rightarrow \mathrm{Dx}=0.0463 \times \frac{150}{0.25 \times \pi \times 0.8^{2}}=13.826 \mathrm{menit} / \mathrm{m}^{2}
$$

Maka diperoleh durasi pengeboran selama 13.826 menit $/ \mathrm{m}^{2}$, dengan tebal sebesar 2 meter, untuk mendapatkan durasi pengeboran untuk tiap meter maka durasi pengeboran menjadi:

$\mathrm{Dx} *=\frac{\mathrm{D}}{\mathrm{h}}=\frac{13.826}{2}=6.913 \frac{\mathrm{menit}}{\mathrm{m}^{2}} / \mathrm{m}$

\section{Menghitung Durasi Pengeboran Berdasarkan Elaborasi Data Bor Log}

Selanjutnya akan dibahas cara menghitung durasi pengeboran sesuai lapisan tanah hasil elaborasi bor log, contoh data pada tabel 6. dengan keterangan data yang sama dengan contoh sebelumnya (proyek 2)

- Kita telah mengetahui hasil elaborasi data bor log proyek 2 yaitu kedalaman 0 sampai dengan 8 meter merupakan tanah clay konsistensi stiff, maka durasi pengeboran untuk lapisan tanah tersebut adalah :

$\mathrm{DE}=6.913+6.913+5.185+5.185+6.913+6.913+7.489+7.489$

$\mathrm{DE}=53$ menit $/ \mathrm{m}^{2}$

Durasi pengeboran untuk tanah clay konsistensi stiff $\left(\mathrm{N}_{\mathrm{Spt}}{ }^{*}=12\right)$ selama 53.000 menit/m², dengan ketebalan 8 meter.

Tabel 6. Contoh hasil durasi pengeboran berdasarkan lapisan tanah hasil elaborasi data bor log proyek 2

\begin{tabular}{|c|c|c|c|c|c|c|c|}
\hline \multirow[b]{2}{*}{ Elevasi } & \multirow[b]{2}{*}{$\mathrm{Ni}$} & \multirow[b]{2}{*}{ Dx (menit/m²) } & \multirow[b]{2}{*}{ Dx* (menit $\left./ \mathrm{m}^{2} / \mathrm{m}^{\prime}\right)$} & \multicolumn{4}{|c|}{ Mengikuti Elaborasi Bor Log } \\
\hline & & & & $\mathrm{Ni}^{*}$ & $\begin{array}{c}\text { Tebal } \\
\text { Lapisan }\end{array}$ & $\begin{array}{c}\text { Tanah \& } \\
\text { Konsistensinya }\end{array}$ & $\begin{array}{c}\mathrm{DE} \\
\left(\text { menit } / \mathrm{m}^{2}\right)\end{array}$ \\
\hline \multirow[b]{2}{*}{-2} & \multirow{2}{*}{12} & \multirow{2}{*}{13.826} & 6.913 & \multirow{8}{*}{12} & \multirow{8}{*}{8} & \multirow{8}{*}{ Clay, Stiff } & \multirow{8}{*}{53} \\
\hline & & & 6.913 & & & & \\
\hline & \multirow{2}{*}{9} & \multirow{2}{*}{10.37} & 5.185 & & & & \\
\hline-4 & & & 5.185 & & & & \\
\hline & \multirow{2}{*}{12} & \multirow{2}{*}{13.826} & 6.913 & & & & \\
\hline-6 & & & 6.913 & & & & \\
\hline & \multirow{2}{*}{13} & \multirow{2}{*}{14.978} & 7.489 & & & & \\
\hline-8 & & & 7.489 & & & & \\
\hline & \multirow{2}{*}{18} & \multirow{2}{*}{20.739} & 10.37 & \multirow{8}{*}{16} & \multirow{8}{*}{8} & \multirow{8}{*}{$\begin{array}{c}\text { Clay, Very } \\
\text { Stiff }\end{array}$} & \multirow{8}{*}{73.74} \\
\hline-10 & & & 10.37 & & & & \\
\hline & \multirow{2}{*}{15} & \multirow{2}{*}{17.283} & 8.641 & & & & \\
\hline-12 & & & 8.641 & & & & \\
\hline & \multirow{2}{*}{15} & \multirow{2}{*}{17.283} & 8.641 & & & & \\
\hline-14 & & & 8.641 & & & & \\
\hline & \multirow{2}{*}{16} & \multirow{2}{*}{18.435} & 9.217 & & & & \\
\hline-16 & & & 9.217 & & & & \\
\hline & & & 6.337 & & & & \\
\hline-18 & 11 & $12.6 / 4$ & 6.337 & 11 & 2 & Clay, stift & $12.6 / 4$ \\
\hline & 22 & 25348 & 12.674 & & & & \\
\hline-20 & 22 & 25.348 & 12.674 & & & Clay, Very & \\
\hline & 23 & 265 & 13.25 & 23 & 4 & Stiff & 51.848 \\
\hline-22 & 23 & 20.5 & 13.25 & & & & \\
\hline & 33 & 38027 & 19.011 & 33 & 2 & Clav Hard & ברבת 38 \\
\hline-24 & 33 & 38.022 & 19.011 & 33 & 2 & сіау, нага & 38.022 \\
\hline & 38 & 43783 & 21.891 & & 2 & Sand Dense & 43783 \\
\hline-26 & 38 & 43.783 & 21.891 & 38 & 2 & sana, Dense & \\
\hline & 22 & 25348 & 12.674 & 22 & 2 & Sand, Medium & 25348 \\
\hline-28 & 22 & 25.348 & 12.674 & 22 & 2 & Dense & 25.348 \\
\hline
\end{tabular}




\section{Input Data untuk Analisis}

Hasil olah data yang sudah melalui tahapan elaborasi data bor log, perhitungan durasi pengeboran tiap rasio $\mathrm{N}_{\mathrm{Spt}}$ pada bor log, dan menghitung durasi pengeboran berdasarkan elaborasi data bor log akan menghasilkan durasi pengeboran, nilai $\mathrm{N}_{\mathrm{Spt}}$ berdasarkan elaborasi data bor $\log \left(\mathrm{N}_{\mathrm{Spt}}{ }^{*}\right)$, dan tebal lapisan untuk setiap klasifikasi jenis tanah. Data disusun sesui klasifikasi jenis tanah (lihat gambar 3).

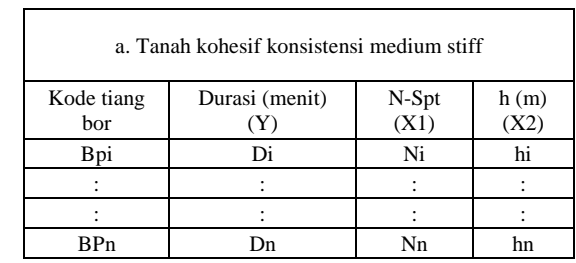

\begin{tabular}{|c|c|c|c|}
\hline \multicolumn{4}{|c|}{ c. Tanah kohesif konsistensi very stiff } \\
\hline $\begin{array}{c}\text { Kode tiang } \\
\text { bor }\end{array}$ & $\begin{array}{c}\text { Durasi (menit) } \\
\text { (Y) }\end{array}$ & $\begin{array}{c}\text { N-Spt } \\
(\mathrm{X} 1)\end{array}$ & $\begin{array}{c}\text { h (m) } \\
(\mathrm{X} 2)\end{array}$ \\
\hline Bpi & Di & $\mathrm{Ni}$ & $\mathrm{hi}$ \\
\hline$:$ & $:$ & $:$ & $:$ \\
\hline$:$ & $:$ & $:$ & $:$ \\
\hline BPn & Dn & Nn & hn \\
\hline
\end{tabular}

\begin{tabular}{|c|c|c|c|}
\hline \multicolumn{5}{|c|}{ e. Tanah nonkohesif konsistensi dense to very dense } \\
\hline $\begin{array}{c}\text { Kode tiang } \\
\text { bor }\end{array}$ & $\begin{array}{c}\text { Durasi (menit) } \\
(\mathrm{Y})\end{array}$ & $\begin{array}{c}\mathrm{N}-\mathrm{Spt} \\
(\mathrm{X} 1)\end{array}$ & $\begin{array}{c}\mathrm{h}(\mathrm{m}) \\
(\mathrm{X} 2)\end{array}$ \\
\hline Bpi & $\mathrm{Di}$ & $\mathrm{Ni}$ & $\mathrm{hi}$ \\
\hline$:$ & $:$ & $:$ & $:$ \\
\hline$:$ & $:$ & $:$ & $:$ \\
\hline BPn & Dn & $\mathrm{Nn}$ & $\mathrm{hn}$ \\
\hline
\end{tabular}

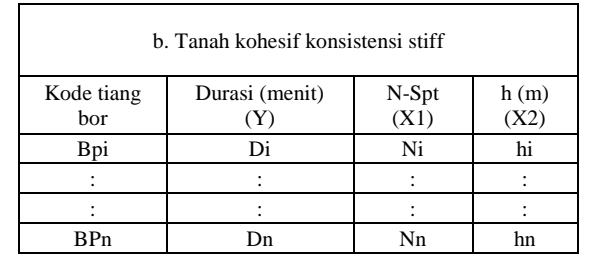

\begin{tabular}{|c|c|c|c|}
\hline \multicolumn{4}{|c|}{ d. Tanah kohesif konsistensi hard } \\
\hline $\begin{array}{c}\text { Kode tiang } \\
\text { bor }\end{array}$ & $\begin{array}{c}\text { Durasi (menit) } \\
\text { (Y) }\end{array}$ & $\begin{array}{c}\text { N-Spt } \\
\text { (X1) }\end{array}$ & $\begin{array}{c}\text { h (m) } \\
\text { (X2) }\end{array}$ \\
\hline Bpi & Di & Ni & hi \\
\hline$:$ & $:$ & $:$ & $:$ \\
\hline$:$ & $:$ & $:$ & $:$ \\
\hline BPn & Dn & Nn & hn \\
\hline
\end{tabular}

Gambar 3. Penyusunan Input untuk Dianalisis

\section{Analisis dan Pembahasan}

Hasil elaborasi seluruh data bor log di semua proyek, maka jenis tanah diklasifikasikan menjadi:

a. Tanah kohesif konsistensi medium stiff

b. Tanah kohesif konsistensi stiff

c. Tanah kohesif konsistensi very stiff

d. Tanah kohesif konsistensi hard

e. Tanah nonkohesif konsistensi dense to very dense

Berdasarkan interpretasi tabel Correlations (Pearson Correlation) menyatakan variabel Tebal Lapisan lebih berpengaruh terhadap variabel Durasi Pengeboran dibandingkan variabel $\mathrm{N}_{\text {Spt, }}$ hal ini berlaku untuk semua klasifikasi jenis tanah yang dianalisis. (Lihat tabel 7.)

Tabel 7. Rangkuman tabel Correlations dan tabel ANOVA

\begin{tabular}{|c|c|c|c|c|}
\hline \multicolumn{2}{|c|}{ Klasifikasi Tanah } & \multirow{2}{*}{$\begin{array}{c}\text { Interpretasi Tabel } \\
\text { Correlations } \\
\text { Variabel Tebal Lapisan lebih } \\
\text { berpengaruh terhadap } \\
\text { variabel Durasi Pengeboran } \\
\text { dibandingkan variabel } \mathrm{N}_{\mathrm{Spt}}\end{array}$} & \multicolumn{2}{|c|}{ Interpretasi Tabel ANOVA } \\
\hline Jenis Tanah & Konsistensi & & $\begin{array}{l}\text { F hitung }> \\
\text { F tabel, } \\
\text { maka Ho } \\
\text { ditolak }\end{array}$ & $\begin{array}{l}\text { F hitung memiliki } \\
\text { tingkat } \\
\text { signifikansi lebih } \\
\text { kecil dari } 0.05\end{array}$ \\
\hline \multirow{4}{*}{$\begin{array}{l}\text { Tanah } \\
\text { Kohesif }\end{array}$} & Medium Stiff & $\sqrt{2}$ & $\checkmark$ & $\checkmark$ \\
\hline & Stiff & $\checkmark$ & $\checkmark$ & $\checkmark$ \\
\hline & Very Stiff & $\checkmark$ & $\checkmark$ & $\checkmark$ \\
\hline & Hard & $\checkmark$ & $\checkmark$ & $\checkmark$ \\
\hline $\begin{array}{c}\text { Tanah } \\
\text { Nonkohesif }\end{array}$ & $\begin{array}{c}\text { Dense to } \\
\text { Very Dense }\end{array}$ & $\checkmark$ & $\checkmark$ & $\checkmark$ \\
\hline
\end{tabular}

Tabel 7., interpretasi tabel ANOVA di semua klasifikasi jenis tanah yang dianalisis menyatakan :

a. F hitung > F tabel, maka Ho ditolak

Ho ditolak, maka variabel independen secara signifikan dan positif berpengaruh terhadap variabel dependen. 
b. F hitung memiliki tingkat signifikansi lebih kecil dari 0.05. Maka model regresi dapat dipakai untuk memprediksi nilai Durasi Pengeboran, atau dapat dikatakan variabel $\mathrm{N}_{\mathrm{Spt}}$ dan Tebal Lapisan secara bersama-sama berpengaruh terhadap Durasi Pengeboran.

Berdasarkan tabel Coefficients, uji t di semua klasifikasi jenis tanah yang dianalisis menyatakan nilai signifikansi variabel Tebal Lapisan < probabilitas 0.05, artinya ada pengaruh variabel Tebal Lapisan terhadap Durasi Pengeboran, Namun hanya tanah kohesif konsistensi stiff yang menyatakan nilai signifikansi variabel $\mathrm{N}_{\mathrm{Spt}}>$ probabilitas 0.05, artinya tidak ada pengaruh variabel $\mathrm{N}_{\mathrm{Spt}}$ terhadap Durasi Pengeboran. Maka persamaan regresi linear berganda dari tanah kohesif konsistensi stiff tidak bisa menjadi prediktor Durasi Pengeboran. (Lihat Tabel 8.)

Tabel 8. Rangkuman hasil uji t di semua klasifikasi jenis tanah yang dianalisis

\begin{tabular}{cccc}
\hline \multicolumn{2}{c}{ Klasifikasi Tanah } & \multicolumn{3}{c}{ Uji t } \\
\hline \multirow{3}{*}{ Jenis Tanah } & Konsistensi & $\begin{array}{c}\text { Ada pengaruh variabel } \mathrm{N}_{\text {Spt }} \\
\text { terhadap Durasi } \\
\text { Pengeboran }\end{array}$ & $\begin{array}{c}\text { Ada pengaruh variabel Tebal } \\
\text { Lapisan terhadap Durasi } \\
\text { Pengeboran }\end{array}$ \\
\cline { 2 - 4 } Tanah Kohesif & Medium Stiff & $\boldsymbol{V}$ & $\boldsymbol{\checkmark}$ \\
\cline { 2 - 4 } & Stiff & $\mathbf{X}$ & $\boldsymbol{\checkmark}$ \\
\cline { 2 - 4 } $\begin{array}{c}\text { Tanah Stiff } \\
\text { Nonkohesif }\end{array}$ & $\begin{array}{c}\text { Dense to Very } \\
\text { Dense }\end{array}$ & $\boldsymbol{V}$ & $\boldsymbol{V}$ \\
\hline
\end{tabular}

Berdasarkan nilai koefisien determinansi (R Square), tanah kohesif konsistensi medium stiff dan tanah nonkohesif konsistensi dense to very dense memiliki tingkat hubungan atau kekuatan antara variabel dependen dan independen yang sedang, dengan alasan tersebut maka hanya persamaan garis regresi linear yang memiliki tingkat hubungan yang kuat saja untuk dipakai sebagai prediktor durasi pengeboran pada studi ini. (Lihat Tabel 9.)

Tabel 9. Rangkuman persamaan garis regresi, nilai R Square, dan tingkat hubungan di semua klasifikasi jenis tanah yang dianalisis Tanah Kohesif

\begin{tabular}{cccc}
\hline Konsistensi & Persamaan Garis Regresi & $\begin{array}{c}\mathrm{R} \\
\text { Square }\end{array}$ & $\begin{array}{c}\text { Tingkat } \\
\text { Hubungan }\end{array}$ \\
\hline Medium Stiff & $\mathrm{D}=-24.166+4.093 \mathrm{X} 1+2.645 \mathrm{X} 2$ & 0.457 & Sedang \\
\hline Stiff & $\mathrm{D}=-1.749+0.011 \mathrm{X} 1+6.018 \mathrm{X} 2$ & 0.762 & Kuat \\
\hline Very Stiff & $\mathrm{D}=-12.613+0.489 \mathrm{X} 1+10.259 \mathrm{X} 2$ & 0.767 & Kuat \\
\hline Hard & $\mathrm{D}=-77.306+1.681 \mathrm{X} 1+24.320 \mathrm{X} 2$ & 0.794 & Kuat \\
\hline Tanah Nonkohesif & & \\
\hline Konsistensi & Persamaan Garis Regresi & $\mathrm{R}$ & Tingkat \\
& Square & Hubungan \\
\hline Dense to Very Dense & $\mathrm{D}=-13.500+0.961 \mathrm{X} 1+9.432 \mathrm{X} 2$ & 0.542 & Sedang \\
\hline
\end{tabular}

Karena di semua klasifikasi jenis tanah yang dianalisis menyatakan Standard Error of the Estimate lebih kecil dari stadar deviasi Durasi Pengeboran, maka model regresi lebih baik dalam bertindak sebagai prediktor Durasi Pengeboran daripada rata-rata Durasi Pengeboran itu sendiri. (Lihat tabel 10.)

Tabel 10. Nilai Standard Error of the Estimate dan Stadar Deviasi di semua klasifikasi jenis tanah yang dianalisis

\begin{tabular}{ccc}
\hline & Tanah Kohesif & \\
\hline Konsistensi & Standard Error of the Estimate $\left(\right.$ menit $\left./ \mathrm{m}^{2}\right)$ & Stadar Deviasi $\left(\mathrm{menit}^{2} \mathrm{~m}^{2}\right)$ \\
\hline Medium Stiff & 6.8138 & 9.074 \\
\hline Stiff & 7.216 & 14.612 \\
\hline Very Stiff & 10.974 & 22.527 \\
\hline Hard & 20.377 & 44.485 \\
\hline Konsistensi & Tanah Nonkohesif & \\
\hline Dense to Very Dense & Standard Error of the Estimate $\left(\mathrm{menit} / \mathrm{m}^{2}\right)$ & Stadar Deviasi $\left(\mathrm{menit} / \mathrm{m}^{2}\right)$ \\
\hline
\end{tabular}




\section{KESIMPULAN}

Hasil studi menunjukkan beberapa hal berikut ini:

1. Hasil analisis elaborasi data bor log di semua proyek, untuk tanah kohesif terdiri dari jenis tanah clay dan silt dan tanah nonkohesif terdiri dari tanah sand, dapat diklasifikasikan menjadi:

a. Tanah kohesif konsistensi medium stiff

b. Tanah kohesif konsistensi stiff

c. Tanah kohesif konsistensi very stiff

d. Tanah kohesif konsistensi hard

e. Tanah nonkohesif konsistensi dense to very dense

2. Analisis regresi linear berganda menghasilkan persamaan garis regresi dengan dengan variabel dependen yaitu durasi pengeboran (D) yang tergantung pada variabel independen yaitu $\mathrm{N}_{\mathrm{Spt}}$ (X1) dan tebal lapisan (X2)

3. Hasil analisis untuk mencari prediksi durasi pengeboran dengan tingkat hubungan atau kekuatan yang kuat dan dengan uji t dan uji f yang memiliki nilai signifikansi < probabilitas 0.05 , yaitu:

a. Jenis tanah kohesif konsistensi hard memiliki tingkat hubungan yang kuat dengan nilai r square sebesar 0.794, persamaan garis regresi untuk tanah tersebut:

$$
\mathrm{D}=-77.306+1.681 \mathrm{X} 1+24.320 \mathrm{X} 2
$$

b. Jenis tanah kohesif konsistensi very stiff memiliki tingkat hubungan yang kuat dengan nilai $\mathrm{r}$ square sebesar 0.767, persamaan garis regresi untuk tanah tersebut:

$$
\mathrm{D}=-12.613+0.489 \mathrm{X} 1+10.259 \mathrm{X} 2
$$

\section{DAFTAR PUSTAKA}

America. Illinois Department of Transportation. (2016). "Specific Task Training Program Drilled Shaft Foundation Construction Inspection S-32 Class Reference Guide”. Springfield: Bureau of Construction.

Anondho, B. dan Gregorius Sandjaja. (2008). “Analisis Risiko Durasi Pelaksanaan Bored Pile di Jakarta Tahap I: Penentuan Variabel Probabilistik Durasi Kegiatan Bored Pile”. Jakarta: Lembaga Penelitian Universitas Tarumanagara

Cartlidge, Duncan. (2015). “Construction Project Manager’s Pocket Book”. Abingdon: Routledge

Das, Braja M. (2010). “Principles of Geotechnical Engineering ( $7^{\text {th }}$ ed.)”. Stamford: Cengage Learning

Das, Braja M. (2011). "Principles of Foundation Engineering ( $7^{\text {th }}$ ed.)”. Stamford: Cengage Learning

Ghozali, Imam. (2016). “Aplikasi Analisis Multivariate dengan Program IBM SPSS 23 (Edisi 8)”. Semarang: Badan Penerbit Universitas Diponegoro

Harinaldi. (2005). “Prinsip-Prinsip Statistik untuk Teknik dan Sains”. Jakarta: Erlangga

Husen, Abrar. (2011). “Manajemen Proyek: Perencanaan, Penjadwalan, dan Pengendalian Proyek”. Yogyakarta: ANDI

Rahardjo, Paulus. P. (2005). “Manual Pondasi Tiang edisi 3”. Program Pasca Sarjana Teknik Sipil, Universitas Khatolik Parahyangan.

Roskarina. (2008). "Pengaruh Konsistensi / Kepadatan Tanah Terhadap Biaya dan Durasi Perancangan Tiang Pancang”. Jakarta :Fakultas Teknik Sipil Universitas Tarumanagara

Seeley, Ivor H. (1995). “Building Technology (5 ${ }^{\text {th }}$ ed.)”. London: Macmillan

Sugiyono. (2007). "Statistika untuk Penelitian". Bandung: Alfabeta

Sutanto, Rachman. (2005). “Dasar-Dasar Ilmu Tanah: Konsep dan Kenyataan”. Yogyakarta: Penerbit Kanisius.

Walpole, Ronald E., Raymond H. Myers, Shaton L. Myers, \& Keying Ye. (2012). "Probablility \& Statistics for Engineers \& Scientics 9th Edition”. Boston: Pearson Education, Inc.

Yassin, Hendro. (2019). "Durasi Pengeboran". Hasil Komunikasi Dua Arah: 22 Maret 2019. Universitas Trisakti 
